\title{
VIOLÊNCIA PSICOLÓGICA COMO MECANISMO DE CENSURA AOS DIREITOS CIVIS E UNIVERSAIS DAS MULHERES
}

\section{PSYCHOLOGICAL VIOLENCE AS A CENSORSHIP MECHANISM FOR WOMEN'S CIVIL AND UNIVERSAL RIGHTS}

\author{
Dirceu Pereira Siqueira ${ }^{1}$ \\ Carlos Alexandre Preto Moraes ${ }^{2}$ \\ Valesca Luzia de Oliveira Passafaro ${ }^{3}$
}

\section{RESUMO}

Esta pesquisa tem como principal objetivo pontuar os mecanismos de violência contra mulher, que começam com a violência psicológica e culminam no feminicídio. A Constituição Federal de 1988 proíbe toda forma de discriminação contra qualquer cidadão, uma vez esta prejudica a aautonomia, a liberdade, o desenvolvimento intelectual e profissional, a participação política, a educação, a saúde e a manutenção da vida. Para tanto, foi realizada uma revisão bibliográfica para verificar a influência da violência psicológica contra a mulher nos casos de feminicídio. Os resultados obtidos apontam que as relações de poder, sejam de pessoa para pessoa ou fruto do sistema social, acabam por favorecer a violência diante da tentativa de manutenção da estrutura social, do patriarcado e do poder vigente, contexto em que a violência empregada nas formas física e psicológica culmina no feminicídio.

\footnotetext{
${ }^{1}$ Coordenador e Professor Permanente do Programa de Doutorado e Mestrado em Direito do Centro Universitário Cesumar (UniCesumar); Pós-doutor em Direito pela Faculdade de Direito da Universidade de Coimbra (Portugal), Doutor e Mestre em Direito Constitucional pela Instituição Toledo de Ensino - ITE/Bauru, Especialista Lato Sensu em Direito Civil e Processual Civil pelo Centro Universitário de Rio Preto, Pesquisador Bolsista Modalidade Produtividade em Pesquisa para Doutor - PPD - do Instituto Cesumar de Ciência, Tecnologia e Inovação (ICETI), Professor nos cursos de graduação em direito da Universidade de Araraquara (UNIARA) e do Centro Universitário Unifafibe (UNIFAFIBE), Professor Convidado do Programa de Mestrado University Missouri State - EUA, Editor da Revista Direitos Sociais e Políticas Públicas (Qualis B1), Consultor Jurídico, Parecerista, Advogado. Universidade Cesumar - Unicesumar. Paraná. lattes: http://lattes. cnpq.br/3134794995883683 ORCID: https://orcid.org/0000-0001-9073-7759. E-mail: dpsiqueira@ uol.com.br²

2 Professor Permanente do Programa de Doutorado e Mestrado em Direito do Centro Universitário Cesumar (UniCesumar), Pós-doutor em Direito pelo Centro Universitário Cesumar (UniCesumar), Doutor em Direito pela FADISP; Doutor em Ciências da Educação pela UPAP, Mestre em Direito pelo Centro Universitário Cesumar (UniCesumar), Pesquisador Bolsista - Modalidade Produtividade em Pesquisa para Doutor PPD - do Instituto Cesumar de Ciência, Tecnologia e Inovação (ICETI), Editor chefe da Revista de Constitucionalização do Direito Brasileiro - RECONTO, Advogado. Universidade Cesumar - Unicesumar. Paraná. lattes: http://lattes.cnpq.br/7327808122990666. ORCID: https://orcid.org/0000-0002-2230-0368. E-mail: camoraes.adv @ hotmail.com

${ }^{3}$ Coordenadora e Professora de Pós-Graduação em Psicologia Jurídica e Ciências Criminais. Mestre em Ciências Jurídicas - Direitos da Personalidade; é Especialista em Psicanálise pelo Núcleo de Ensino Paranaense, (NECPAR); Especialização em Psicologia Jurídica e Ciências Criminais; Especialização em Docência no Ensino Superior: Tecnologias Educacionais e Inovação. Psicóloga Clínica e Supervisora Clínica; - Área Psicanalítica. Consultora na grande área Forense. Atuou como docente de Psicologia Jurídica no departamento de Direito na Unicesumar, Docente em Psicologia Forense no departamento de Direito e Psicologia e Direitos Humanos no departamento de Psicologia na instituição Unifatecie. Pesquisadora nas áreas de Psicopatologia e Psicologia social e Direitos da Personalidade. Departamento de Pós Graduação em Ciências Jurídicas - Unicesumar. Universidade Cesumar - Unicesumar. Paraná. lattes: http://lattes.cnpq.br/6418420686303481 E-mail: valescapassafaro @ hotmail.com
} 
Palavras-chave: Direitos das Mulheres; Estruturas de Poder; Feminicídio; Patriarcado; Violência.

\begin{abstract}
This paper aims to analyze the mechanisms of violence against women, which start with psychological violence and culminate in femicide. The Brazilian Federal Constitution of 1988 forbids any form of discrimination against any citizen, since this undermines autonomy, freedom, intellectual and professional development, political participation, education, health and the maintenance of life. To this end, a bibliographic review was carried out to verify the influence of psychological violence against women in cases of femicide. The selected results point out how power relations, whether people to people or fruits of the social system, end up violating the attempt to maintain the social structure, make patriarchy and can watch, a context in which the violence used in physical and psychological forms culminates in femicide.
\end{abstract}

Keywords: Women's Rights; Power Structures; Femicide; Patriarchate; Violence.

\title{
INTRODUÇÃO
}

Esse trabalho objetiva analisar o fenômeno da violência contra a mulher e a quebra de seus direitos civis, destacando que, em muitos casos, esse processo pode culminar, inclusive, na morte de muitas cidadãs. $\mathrm{O}$ aumento do número de casos de feminicídio no Brasil é alarmante, mesmo em face de leis de referência, que deveriam ser suficientes para inibir tal violência.

Este trabalho, então, buscou entender o patriarcado como estrutura propulsora dos processos de violência contra a mulher, tendo como premissa que a violência psicológica é um dos mecanismos inicias, ou instrumento inicial, para a opressão das mulheres que não se sujeitam à estrutura patriarcal.

Sobre esse contexto, Hannah Arendt e Saffioti apontam que qualquer seja a estrutura de poder vigente, a ideologia que a determina tentará se manter a qualquer custo, utilizando todos os meios, sejam físicos, psíquicos e/ou sociais, com o objetivo de garantir intacto o seu modelo hierárquico que, no contexto deste trabalho, determina a desigualdade de gênero.

É notável nos sistemas midiáticos inúmeras notícias de morte de mulheres pelo simples fato de serem mulheres, ou seja, a motivação dos crimes tem relação direta com a estruturação do gênero na sociedade.

Tais dados se tornam ainda mais alarmantes diante do fato de que muitas das vítimas têm acesso aos sistemas de segurança e os procuram para a sua proteção, mas, mesmo em face de denúncia e da busca por ajuda, não conseguem a adequada proteção por parte do Estado. 
Todo este cenário de morte de mulheres por seus companheiros ou ex-companheiros, que se repete continuamente, demonstra a necessidade de um olhar aprofundado para este fenômeno, buscando soluções que visem coibir as formas de violência e de opressão contra as mulheres, garantindo proteção às vítimas e punição adequada aos agressores.

Tal olhar e cuidado são necessários para que se oportunize a essas mulheres voz e espaço social para que se sintam livres e seguras, podendo, inclusive, lutar contra a opressão instituída e contra as violências a que estão expostas em razão do patriarcado.

Por este caminho, entender que a violência psicológica é determinante nos processos que mantêm intacta a situação de vulnerabilidade das mulheres é fundamental.

Ainda, não há como ignorar que essa forma de agressão, contínua e, muitas vezes, oculta, é responsável por inibir e abafar as vozes femininas e muitas das ações que buscam a igualdade de gênero.

Por mais que a violência física seja mais facilmente identificada, a violência psicológica é ulterior a todas as ações determinantes da estrutura de poder masculino e sua forma passiva e silenciosa é tão ou mais grave que qualquer outra forma de violência contra a mulher.

A Lei Maria da Penha (Lei $\left.n^{\circ} 11.340 / 2006\right)$, expõe em seu artigo $7^{\circ}$, inciso II, que a violência psicológica é uma das formas de violência doméstica e familiar contra a mulher, sendo entendida como "qualquer conduta que lhe cause dano emocional e diminuição da autoestima ou que lhe prejudique e perturbe o pleno desenvolvimento ou que vise degradar ou controlar suas ações, comportamentos, crenças e decisões", mediante "ameaça, constrangimento, humilhação, manipulação, isolamento, vigilância constante, perseguição contumaz, insulto, chantagem, ridicularizarão, exploração e limitação do direito de ir e vir" ou "qualquer outro meio que lhe cause prejuízo à saúde psicológica e à autodeterminação". (BRASIL, 2006).

Desta forma, entende-se que a violência psicológica não costuma deixar marcas no corpo, porém, é capaz ocasionar graves marcas na estima, na autoconfiança e na autonomia da mulher, causando danos irreversíveis à sua integridade.

Por mais silenciosa que seja, a violência psicológica contra mulher é muito comum, inclusive, pode ser encontrada com facilidade depois de apurados os acontecimentos cotidianos da relação da vítima de feminicídio com o agressor, na relação denunciada nos relatos de familiares, amigos e vizinhos das vítimas de violência física.

Ou seja, antes de tirar a vida da vítima, geralmente houve uma série de ações entendidas como violência psicológica, sendo este um importante fator para a ocorrência do feminicídio. 
Pode-se, ainda, perceber que a morte da mulher, no contexto do feminicídio, ocorre após a sua oposição aos processos e efeitos perversos da violência psicológica e à obediência à estrutura patriarcal.

Dessa forma, este trabalho obteve como resposta ao estudo proposto que é inerente aos processos de manutenção de estruturas de poder e de ideologias de grupo a violência como forma de afastar, calar e coibir indíviduos que atentem contra a organização instituída.

Dessa forma, faz-se necessário o entendimento dos processos que mantêm as formas de violência contra a mulher para que se combata os mecanismos que impedem ou abafam a luta pela igualdade entre os gêneros, bem como para que sejam encontradas formas eficazes de garantia dos direitos civis e universais das mulheres.

\section{A VIOLÊNCIA COMO SUBSTRATO DAS RELAÇÕES DE PODER}

Hannah Arendt (1994), em seu livro intitulado Da Violência, aponta que o século XX foi um período de lutas e de revoluções importantes, mas também de crueldade. O conceito de crueldade e de violência, para Arendt, perpassa o formato físico. Desta forma, a formulação da violência é, sobretudo, subjetiva, estrutural e utilizada para a manutenção de forças sociais e políticas.

A autora pondera ainda que a violência necessita sempre de instrumentos, ou seja, de um meio para o seu fim, sendo esta estrutura a base que justifica a violência. Contudo, o risco que se coloca nessa estruturação é o da contaminação dos objetivos, que passariam a ser dominados pelos meios ou pela violência empregada nos meios. (ARENDT, 1994).

Para Arendt:

uma vez que a violência - distinta do poder, força ou vigor - necessita sempre de instrumentos [...]. A própria substância da violência é regida pela categoria meio/objetivo cuja mais importante característica, se aplicada às atividades humanas, foi sempre a de que os fins correm o perigo de serem dominados pelos meios, que justificam e que são necessários para alcançá-los. (ARENDT, 1994, p. 4).

Nas palavras da autora:

penso ser um triste reflexo do atual estado da ciência política que nossa terminologia sobre violência não distinga entre palavras-chave tais como "poder" (power), "vigor" (strenght), "força" (force), "autoridade" e, por fim, "violência" - as quais se referem a fenômenos distintos e diferentes". (ARENDT, 1994, p. 36).

É claro que com estas palavras Arendt não trata de questões meramente linguísticas ou de significado de termos que são, entre si, sinônimos da mesma variável. 
A autora trata, na verdade, de expor um processo de imposição de poder pelas classes sociais dominantes, que utilizam diversas formas de violência, sob múltiplas terminologias, para impor o pensamento de seus grupos políticos e sociais a fim de alcançar ou manter o seu poder, sendo a violência o instrumento que efetiva esses objetivos propostos. (ARENDT, 1994).

O uso de violência, nesse sentido, evidencia a defesa estrutural, ideológica e política que dispende energia, violentamente, contra cidadãos que pensam de forma diferente, tornando-os alvos dessas ideologias. "Os termos poder, vigor, força, autoridade e violência são tomados como sinônimos porque têm, na compreensão comum, a mesma função, isto é, indicar "quem domina quem". (ARENDT, 1994, p. 36).

Deste modo, a violência estaria a serviço da dominação e, neste campo, valeria usar força, vigor, autoridade e poder para tornar a própria existência da estrutura ideológica dominante violenta. Segundo Arendt, "os fins correm o perigo de serem dominados pelos meios, que justificam e que são necessários para alcançá-los”. (ARENDT, 1994, p. 4).

Exemplifica tal cenário os processos de violência atráves das estruturas de poder e as atrocidades que aconteceram na China, no século XX. Rios (1973) narra o movimento conhecido como a Grande Revolução Cultural Proletária (também conhecida como Revolução Cultural Chinesa), uma profunda campanha político-ideológica levada e desenvolvida a partir de 1966, por Mao Tsé-Tung, líder político que tentou movimentar a população a favor de seus objetivos ideológicos, ditos por ele como "das massas para as massas", influenciando uma sociedade faminta e sem acesso ao ensino básico, que era hierarquizado e elitista.

Quando encontrou resistência a suas ideias nas camadas intelectuais, Mao Tsé-Tung passou a utilizar a violência física. Assim, de forma coercitiva, levou a China para o caminho que desejava. Usou a violência física através da guarda vermelha (grupo formado por jovens estudantes e proletários), que neutralizava quem se opunha às ideias do líder. (RIOS, 1973).

Logo, resta claro que, como Arednt (1994) expõe, a política a serviço de ideologias usa a violência física para alcançar seu objetivo de "obediência".

Para Saffioti (2004), o patriarcado utiliza estrutura semelhante: se não há obediência, há violência. Saffioti, relembrando Hartmann, afirma que o patriarcado pode ser definido como um pacto, um acordo masculino que garante a opressão das mulheres e mantém todas as relações de hierarquia e de solidariedade e as "legalizações" que licenciam e capacitam a categoria masculina a manter o poder, o controle e a sujeição sobre todas as mulheres.

Essas formas de violência empregadas pelo patriarcado se fazem presentes em diversos formatos, perpetuando um ambinte de opressão mesmo frente a supostas vitórias das oprimidas. 
Dessa forma, o sistema patriarcal, mesmo rodeado de discursos e de legislação que protege - ou deveria - as mulheres, busca outras formas, além da violência física, para coibir que estas vivenciem, de fato, a liberdade em todas as áreas de sua vidas, mantendo a opressão ao desenvolvimento livre da mulher enquanto profissional, mantendo a repressão a sua vida amorosa e sexual e interferindo nas suas relações e construções sociais. (SAFFIOTI, 2004).

Ainda para Saffioti (2004), a violência é entendida no imaginário social como aquela de que alguém foi vítima diante de uma ação direta e física, como assaltos, roubos, sequestros, violência no trânsito, etc. Saffioti pontua que as pessoas estão acostumadas com um cotidiano de violência em que acreditam ter sorte se saem ilesas de situações de agressão.

Essa violência, presente e entendida pela sociedade, é palpável porque provoca a ruptura da integridade física da vítima, diferentemente da violência que se apresenta por fenômenos subjetivos, psicológicos e morais, mais difíceis de serem identificados e compreendidos. (SAFFIOTI, 2004).

Sobre isso, Arendt (1994) comenta que mesmo as violências subjetivas alcançam em algum momento seu patamar físico, é o caso da violência psicológica.

Como reafirma Saffioti:

[...] o entendimento popular da violência apoia-se num conceito, durante muito tempo, e ainda hoje, aceito como o verdadeiro e o único. Trata-se da violência como ruptura de qualquer forma de integridade da vítima: integridade física, integridade psíquica, integridade sexual, integridade moral. Observa-se que apenas a psíquica e a moral situam-se fora do palpável. Ainda assim, caso a violência psíquica enlouqueça a vítima, como pode ocorrer - e ocorre com certa frequência, como resultado da prática da tortura por razões de ordem política ou de cárcere privado, isolando-se a vítima de qualquer comunicação via rádio ou televisão e de qualquer contato humano -, ela torna-se palpável. (SOFFIETI, 2004, p. 30).

Saffioti (2004), assim como Arendt (1994), pondera que a violência tem vários formatos e que estes perpassam a forma física, deixando claro que seja na violência psicológica, moral, estrutural ou física, sempre existirá, como base, um desejo de domínio do outro, como é nas relações que determinam a desigualdade entre os gêneros.

Para a autora:

a desigualdade, longe de ser natural, é posta pela tradição cultural, pelas estruturas de poder, pelos agentes envolvidos na trama de relações sociais. Nas relações entre homens e entre mulheres, a desigualdade de gênero não é dada, mas pode ser construída, e o é, com frequência. (SAFFIOTI, 2004, p. 14).

Outra vertente de manifestação da violência aparece quando esta é perpetrada por pessoas comuns, pelos reconhecidos como “agentes do bem”. Este fenômeno é mencionado na 
obra Eichmann em Jerusalém: um relato sobre a banalidade do mal, de Hannah Arendt (1999), na qual a autora analisa o Holocausto comandado por Adolf Hitler e seus agentes.

Na obra, Arendt (1999) não polpa esforços para mostrar que atos de crueldade também podem ser efetuados "por pessoas de bem, pelos cumpridores de normas e regras" e por qualquer "bom soldado" .

Além disso, a obra demonstra que os crimes de guerra e as violências perpretadas durante o Holocausto não foram cometidas por um único "monstro", mas por indivíduos, cumprindo o seu dever moral de obediência à autoridade e às ordens recebidas. Para Arendt (1999), é comum imaginar que o bem é feito pelo bondoso e o mal é feito pelo maldoso, e constatar que isso não é uma regra assombra o ser humano. (ARENDT, 1999).

Para a autora, a violência é percebida no cotidiano, dentro da rotina. Assim, expõe uma ferida, a de que não é apenas o criminoso, ou nas situações de casos excepcionais, mas no movimento do dia a dia que se constrói ou se encontra a violência. (ARENDT, 1999).

Essa percepção faz nascer uma sensação incômoda, a ideia, mesmo que inconsciente, de que os indivíduos precisam se defender a qualquer custo. Uma sensação de perigo que faz com que o ser humano olhe para fora, atuando sobre os demais como se todos fossem ameaças. (ARENDT, 1999).

Acontece que o resultado disso é o surgimento de uma sensação de não-proteção, que leva os indivíduos a estarem sempre na defensiva e a responsabilizarem o outro pelas ações de violência, incuindo as suas. Neste ponto, vê-se que as agressões se justificariam de forma largamente legal, nunca moral, ou seja, o culpado pela violência é sempre o outro, quem provocou no "homem bom" a tentação, ou o motivo, que o levou a agredir e, por isso, o outro deve ser penalizado.

Arendt (1999) dá a esse fenômeno o termo "tentação" e pontua o seguinte exemplo: "se alguém lhe aponta um revólver e diz: mate o seu amigo, se não vou matar você, ele o está tentando, só isso". (ARENDT, 1999, p. 80).

No caso citado por Arendt (1999), supõe-se que houve uma ação agressiva muito requintada, totalmente legalizada e, por tanto, livre de responsabilidade moral, inteiramente legítima, uma violência reconhecida como inerte ou passiva, já que a responsabilidade estaria, teoricamente, com o outro, quem tentou a ação violenta. Cenário que seria totalmente diferente caso a violência fosse palpável e empregada sem a "tentação".

Arendt (1999) deixa claro, então, que é com base em preceitos de moralidade que se constrói a visão que atribui legalidade a certas violências. Exemplificando o contrário da cena anterior, a autora afirma que se uma pessoa, de forma deliberada, resolver, por motivo furtivo, 
tirar a vida de outra pessoa, não será imputada à "tentação" a responsabilidade, pois seu emprego não é legal, mas de peso moral e, portanto, passivo de punição. (ARENDT, 1999).

O conceito de violência proposto por Arendt (1994; 1999), Saffiot (2004) e Marcondes Filho (2001) perpassa a questão de violência física, apontando que essa forma de agressão seria a última forma de expressão diante da oposição à vontade do poder dominante, seja ele político, social ou individual. Por fim, as expressões de violência, tanto na forma física, subjetiva ou moral, fazem parte da estrutura complexa que permite funcionar e manter as formas de opressão e o poder dominante.

Tudo isso ocorre de forma símile na estrutura do patriarcado, cenário em que todas as formas de gênero que não se submetam ao binarismo acabam por sofrer retaliação. Quando existe oposição à força, a autoridade e ao poder no sistema de patriarcado - e por conta do machismo que dele advém - os números da violência contra a mulher tornam-se altíssimos.

Conforme reportagem do Jornal $O$ Globo, em 2019, foram registrados no Brasil:

\begin{abstract}
344 casos de feminicídio - foram 207 episódios consumados e 137 tentativas. A taxa de letalidade é de $60 \%$, com 222 vítimas identificadas, em crimes ocorridos em todos os estados brasileiros, além do Distrito Federal. A média é de 5,31 casos por dia, ou um caso a cada quatro horas e 31 minutos nos primeiros 64 dias do ano". E os dados da ONU confirmam a gravidade: "No Brasil, a taxa de feminicídios é de 4,8 para 100 mil mulheres - a quinta maior no mundo, segundo dados da Organização Mundial da Saúde (OMS). Em 2015, o Mapa da Violência sobre homicídios entre o público feminino revelou que, de 2003 a 2013, o número de assassinatos de mulheres negras cresceu $54 \%$, passando de 1.864 para 2.875 . (CALCAGNO, 2019).
\end{abstract}

A análise desses dados demosntra claramente que por mais que se tenha leis que tentem coibir as violencias efetuadas contra as mulheres, estas não são suficientes ou efetivas. Safiotti (2004) comenta que, caso os homens no patriarcado se sintam ameaçados, utilizam como resposta violações aos direitos fundamentais, civis e à dignidade da mulher.

Tudo isso, num sentindo mais amplo, marca o início da violência psicológica. O que a autora observa é que nenhuma mulher está segura ou livre desta violência, comumente silenciosa e tão perninciosa, que destrói a vítima de forma globalizada. (SAFIOTTI, 2004).

\title{
DA VIOLÊNCIA PSICOLÓGICA
}

Saffioti (2004) considera que, muitas vezes, o homem, em razão do patriarcado, necessita fazer com que a mulher obedeça às suas ordens e que, quando este não consegue sucesso nessa missão, acaba praticando contra ela várias formas de violência. As violências mais comuns às quais as mulheres são expostas são as violências física, psicológica, 
patrimonial, institucional, intra-familiar e conjugal, todas punidas pela Lei Maria da Penha. (BRASIL, 2006).

Conforme dados apurados por Saffioti, no Brasil, antes da promulgação da referida Lei:

$19 \%$ das mulheres declararam, espontaneamente, haver sofrido algum tipo de violência da parte de homens, $16 \%$ relatando casos de violência física, $2 \%$ de violência psicológica, e $1 \%$ de assédio sexual. Quando estimuladas, no entanto, $43 \%$ das investigadas admitem ter sofrido violência sexista, um terço delas relatando ter sido vítimas de violência física, $27 \%$ revelando ter vivido situações de violência psíquica, e $11 \%$ haver experimentado o sofrimento causado por assédio sexual. Trata-se, pois, de quase a metade das brasileiras. Os $57 \%$ restantes devem também ter sofrido alguma modalidade de violência, não as considerando, porém, como tal. (SAFFIOTI, 2004, p. 48).

Neste quadro estatístico interessa a violência psicológica, recorrente e repetitiva. Segundo Hermann (2008), a violência psicológica é toda conduta comissiva ou omissiva que provoque na vítima conduta global de desequilíbrio emocional ao ponto de privá-la de sua autodeterminação e autoestima.

A violência psicológica, para o autor, pode ser efetuada por meio de insultos, ironias, ameaças, perseguição, chantagens, etc. Todos estes atos ocasionam a destruição da saúde psíquica da mulher.

Hermann pontua, ainda, que a violência psicológica atua como mecanismo que destrói a identidade e a autonomia da vítima de forma lenta e reiterada, uma vez que implica em lenta e contínua destruição da identidade e da capacidade de reação e resistência da vítima, sendo comum que progrida para prejuízo importante à sua saúde mental e física. (HERMANN, 2008, p. 109).

Esse tipo de violência contra a mulher ficou mais conhecido, ganhando visibilidade e atenção, na década de 1990, por meio da luta dos movimentos feministas, que reuniam mulheres que percebiam tais violências e se preocupavam com a integridade física e psicológica de outras mulheres em situação de vulnerabilidade.

Atualmente, no Brasil, com a regulamentação da Lei $\mathrm{n}^{\circ} 11.340 / 2006$, a violência psicológica passou a ser reconhecida como crime e se tornou objeto de estudo de muitos pesquisadores, especialmente diante de suas consequências danosas. (BRASIL, 2016).

Freud (1976), menciona como são produzidas as angústias através dos traumas vivenciados pelos indivíduos. $\mathrm{O}$ autor aponta que esses traumas podem ser silenciados, mas nunca esquecidos. Dessa forma, elucida que a única forma de falar sobre o sofrimento advindo de traumas, e de expressar dores silenciadas e ocultas, seria através de sintomas somáticos. 
Em seus estudos sobre a histeria, Freud (1976) vê o trauma como a origem dos conflitos psíquicos, tão importante que é capaz de gerar a sintomatologia física, que é a expressão de sentimentos de "vergonha e silêncio".

Segundo ele, o sintoma seria produzido pela vergonha, um sentimento que impede a pessoa de falar, pensar e, muitas vezes, até mesmo de entender sobre a ação violenta que sofreu/sofre, assim, a vergonha não permitiria o indivíduo de ter ação sobre o que lhe aconteceu, não havendo outra possibilidade de expressão a não ser pelo adoecimento somático ou psíquico. (FREUD, 1976).

Assim, como fator terapêutico, Freud procurou vias para que a vítima pudesse romper o silêncio causado pela vergonha, superando-a, e conseguiu este feito através de dois métodos: a hipnose, mais tarde abandonada por ele, e a escuta da fala de suas pacientes, utilizada até hoje por seus seguidores. A possibilidade da fala proporcionava às mulheres um caminho pelo qual toda experiência traumática tinha a chance de ser relembrada, relatada e elaborada. (FREUD, 1976).

Desta forma, Freud (1976) mostra a importância da fala para o real processo de cura das situações traumáticas. Se aqui se pode fazer uma analogia, vê-se que a Lei Maria da Penha é uma forma de apoio legal e moral que permite, através do acolhimento e da escuta das denúncias, um ambinte de fala no qual essas mulheres podem encontrar o início da cura e da elaboração das violências traumáticas que sofreram. (FREUD, 1976).

Abaixo, observa-se um fragmento de sessão psicanalítica:

Relato: o marido sai para trabalhar e como de costume, passa os cadeados nas portas e janelas, antes de sair adverte a mulher que se vista de forma decente. Ela fica 8 horas diárias, trancda dentro da casa. Sente uma solidão "que dói no peito". Ele volta, entra na casa e fica bravo por que a comida não esta na mesa. Grita e diz "você não faz nada na vida e não consegue nem colocar a comida na mesa. Coração disparado e tremor, ela nunca sabe se vai ficar só nas palavras. Suas roupas são longas e sem decotes. Sai apenas acompanhada do marido e ele diz: se você sorrir pra alguém, eu mato você. Ele a chama de burra, ela acha que é, ela diz não conseguir fazer nada direito, não está bem consigo mesma e não se olha no espelho a quase dois anos. Ele a trouxe à sessão (marido na recepção) "porque tomei remédios para me matar. Não tenho vontade de viver, tive uma avó que também fez isso, isso é de família. Ela pensa que não sabe fazer nada, mas entende que a vida da mulher é sofrimento. Parou de trabalhar a pedido do marido, ele da tudo, só é muito ciumento, por isso ela justifica o motivo de ficar trancada em casa. Ela não se sente bem há algum tempo, ele fala que ela é porca e preguiçosa, "mas eu só não tenho vontade de levantar, ou não consigo, às vezes tenho muito sono. Eu não consigo ser mais eu. Tinha o cabelo bem longo, eu tinha unha longa e eu trabalhava de balconista. A gente casou e eu não preciso mais trabalhar, era só cuidar da casa, vida de madame, mas nem isso eu consigo mais". (FREUD, 1976, p. 88). 
Este relato torna palpável o contexto de muitas mulheres vítimas de violência psicológica e os efeitos perversos a que estão sujeitas. Perdendo a possibilidade de defesa, adoecem e começam a acreditar nas palavras violentas que recebem e a aceitar como normais as ações diárias de agressão. Muitas destas muleres perdem a capacidade de reconhecer as violências que recebem como aquilo que são: crime. (FERENCZI, 1981).

Por isso, torna-se papel do psicoterapeuta - e, em casos emergenciais e pontuais, do profissional de segurança, delegado ou agente - ajudá-las a encarar o que aconteceu, trazendo luz ao processo violento que foi dispensado contra ela, sendo esse amparo de extrema urgência para a real recupeção da vítima. (FERENCZI, 1981).

Ferenczi (1981), ao falar sobre o impacto do trauma na vida do sujeito, demonstrou que este ocorre em dois tempos: a) o acontecimento traumático e b) o não reconhecimento por um terceiro, a quem a vítima pede auxílio, do trauma ocorrido.

Dito isto, Ferenczi recomenda que o psicanalista - e os profissionais que estarão em contato com o traumatizado - dê importância e reconheça o sofrimento que a violência produziu, ajudando assim na elaboração do trauma. (FERENCZI, 1981).

O psicanalista supracitado destaca a necessidade de uma abordagem interdisciplinar de assistência às vítimas de traumas e violência. Ferenczi (1981) afirma que apesar de a experiência traumática ser individual, ela é fenômeno social e externo aos indíviduos, atuando de forma geral e, por isso, necessita de muita disciplina para estancá-la e resolvê-la.

Logo, o primeiro passo seria ajudar a vítima a reconhecer a violência que experimentou e da qual, muitas vezes, não tem consciência, principalmente quando se trata da violência psicológica, ainda mais difícil de ser percebida. (FERENCZI, 1981).

Depois do reconhecimento, o cuidado dispensado a essas vítimas deve contemplar uma rede integrada e de múltiplos saberes. (FERENCZI, 1981).

\section{DO PATRIARCADO À VIOLÊNCIA DE GÊNERO}

No mundo animal, em relação a grande parte das espécies, o macho é o possuidor da maior estatura e força, assim, é dominante sobre a fêmea. No universo dos seres humanos não é muito diferente: o homem sempre foi visto como chefe familiar e provedor.

Como aponta Beauvoir (1980):

[...] há uma diferença biológica entre homem e mulher, mas que é utilizada como base da diferença sociológica, e que tem sido tomada para justificar a supremacia masculina sobre a mulher. Essa concepção de superioridade masculina teve início há cerca de dois mil anos, com o advento da família patriarcal, permanecendo por 
três períodos importantes da história: da escravidão, do feudalismo e do capitalismo. (BEAUVOIR, 1980, p. 43).

Assim, a sociedade se organizou ao longo das eras em diversas formas de entidades familiares, sempre mantendo como líder o homem. Quanto aos registros de Roma, destaca-se uma espécie de família que era administrada por seu ascendente comum mais velho, nomeado como pater, que:

[...] exercia a sua autoridade sobre todos os seus descendentes não emancipados, sobre sua esposa e sobre as mulheres casadas com manus com os seus descendentes. A família era, então, simultaneamente, uma unidade econômica, religiosa, política e jurisdicional. (WALD, 2002, p. 9).

Na Idade Média, o poder do pater, como chefe de família, foi substituído pela Igreja, influenciando, assim, a estrutura e o modelo familiar da época. O ofício familiar era passado de geração em geração e os familiares tinham a responsabilidade de ensinar aos jovens a profissão e os ensinamentos religiosos. (PEREIRA, 2003).

Evidencia-se, nessa época, um único casamento reconhecido e aceito socialmente, o religioso, considerado o penúltimo dos sacramentos cristãos a ser realizado pelos fiéis. Essa união religiosa era realizada antes das partes possuírem uma relação afetiva.

De acordo com Almeida e Tozatti:

\begin{abstract}
historicamente as mulheres foram e ainda são inferiorizadas em diversas sociedades e comumente, educadas para serem submissas, além disso, por séculos elas foram totalmente desprovidas de direitos, sendo inclusive responsabilizadas pelos abusos que sofriam. Preconceito que se mantém até os dias atuais. Como exemplo dos abusos que as mulheres sofreram no decorrer da história podemos citar a Lei nº 11.106 do Código Penal que estava em vigor até 2005 aonde previa que se a vítima de violência sexual se casasse com o agressor esse estaria livre da pena. (ALMEIDA; TOZATTI, 2018, p. 1).
\end{abstract}

O divórcio era algo totalmente rejeitado à época, já que mostrava totalmente contrário ao ensinamento católico e era considerado prejudicial à formação e ao desenvolvimento da prole. Compreendia-se que o homem não podia ser tão petulante ao ponto de separar algo que foi unido por Deus. E, assim, a mulher que sofria algum tipo de violência estava condenada a viver com o mesmo homem pelo resto de sua vida. (PEREIRA, 2003).

Neste âmbito, Rodrigo da Cunha Pereira enfatiza que:

o homem e a mulher se lama sua união sob as bênçãos do céu, transformando-se uma só entidade física e espiritual e de maneira indissolúvel. O sacramento do casamento não poderia ser desfeito pelas partes, somente a morte separaria a união indissolúvel entre um homem e uma mulher, simbolizada através da troca de alianças. (PEREIRA, 2003, p. 25). 
De forma semelhante, nos dias atuais, muitos ainda perpetuam o pensamento medieval: algumas religiões continuam a determinar a obediência e a submissão da mulher ao homem, definindo-as, consequentemente, como únicas formas corretas e aprovadas por Deus de relação entre os dois gêneros.

Saffioti (2004) comenta sobre a estrutura patriarcal e o conceito de gênero da seguinte maneira:

[...] o conceito de gênero carrega uma dose apreciável de ideologia. E qual é esta ideologia? Exatamente a patriarcal, forjada especialmente para dar cobertura a uma estrutura de poder que situa as mulheres muito abaixo dos homens em todas as áreas da convivência humana. É a esta estrutura de poder, e não apenas à ideologia que a acoberta, que o conceito de patriarcado diz respeito. (SAFFIOTI, 2004, p. 115).

Nesse sentido, segundo Scott (1995), a palavra gênero engloba relações idênticas ou iguais, muito diferente do que prega a estrutura do patriarcado, que aborda seres socialmente desiguais. Dessa forma, o patriarcado deve ser discutido, se reconhecendo os conceitos de genêro como uma estrutura que se apropria das relações e as corrompe. Assim, o conceito de gênero deve ser elucidado junto das discussões sobre o patriarcado para apontar as relações disruptivas de dominação-submissão que essa estrutura estabelece. (SAFFIOTI, 2004).

Sobre a terminolgia patriarcado, o seu estabelecimento e sua conceitualização, alguns fatores relevantes se apresentam:

1 - não se trata de uma relação privada, mas civil; 2 - dá direitos sexuais aos homens sobre as mulheres, praticamente sem restrição. Haja vista o débito conjugal explícito nos códigos civis inspirados no Código Napoleônico e a ausência sistemática do tipo penal estupro no interior do casamento nos códigos penais. Há apenas uma década, e depois de muita luta, as francesas conseguiram capitular este crime no Código Penal, não se tendo conhecimento de se, efetivamente, há denúncias contra maridos que violentam suas esposas. No Brasil, felizmente, não há especificação do estuprador. Neste caso, pode ser qualquer homem, até mesmo o marido, pois o que importa é contrariar a vontade da mulher, mediante o uso de violência ou grave ameaça; 3 - configura um tipo hierárquico de relação, que invade todos os espaços da sociedade; 4 - tem uma base material; 5 - corporifica-se; 6 - representa uma estrutura de poder baseada tanto na ideologia quanto na violência. (SAFFIOTI, 2004, p. 57).

Toda esta estrutura de pensamento é a base para que ocorram as violências contra a mulher, da psicológica à física. Tudo isso inserido em um contexto social que tem sua origem em remotas eras e que perpetua uma estrutura onde o homem pode se colocar como superior à mulher.

Essa estrutura faz ser crível uma ideia banal de que o homem é dono da mulher e de seus desejos e que, por isso, pode fazer dela e com ela o que quiser, objetificando-a. Dessa 
forma, a violência derradeira seria o resultado final de todo esse pensamento social determinado pelo patriarcado.

Não é outro o entendimento do Relatório Final da Comissão Parlamentar Mista de Inquérito sobre a Violência contra a Mulher (CPMI) do Congresso Nacional acerca do feminicídio, que é:

a instância última de controle da mulher pelo homem: o controle da vida e da morte. Ele se expressa como afirmação irrestrita de posse, igualando a mulher a um objeto, quando cometido por parceiro ou ex-parceiro; como subjugação da intimidade e da sexualidade da mulher, por meio da violência sexual associada ao assassinato; como destruição da identidade da mulher, pela mutilação ou desfiguração de seu corpo; como aviltamento da dignidade da mulher, submetendo-a a tortura ou a tratamento cruel ou degradante. (BRASIL, 2013, p. 1003).

É importante ressaltar, novamente, que a violência doméstica passa por vários estágios até chegar no feminicídio. Nesse sentido, Patrícia Evans aponta que a violência psicológica verbal é uma forma de manter o controle e o poder autoritário, já que por meio dela o agressor se sente mais poderoso e impõe seus dogmas. Para a autora, a violência verbal é nociva, ataca a natureza e as habilidades de outrem, é manipuladora e controladora e ocorre de forma insidiosa. (EVANS, 2015).

Sobre essa forma de violência, a mencionada autora discorre sobre os mecanismos empregados pelo agressor na contrução de seu agir: procura manter-se distante; tende a contradizer-se (voltando atrás em suas palavras violentas, por vezes se desculpando por elas); menospreza a parceira, ofende e depois finge estar brincando; responsabiliza a parceira por suas atitudes, culpando-a; tem o costume de julgar e criticar; continuamente faz ameaças, xinga, dá ordens e sempre se mostra agressivo ou com raiva. (EVANS, 2015).

Ao manter distância afetiva, o agressor esconde seus própios sentimentos, sonhos, esperanças, revela o mínimo possível de si e sempre demonstra indiferença à parceira. (EVANS, 2015).

Buscando soluções para todo esse cenário de violência, as mulheres muito tiveram que lutar para conquistar todos os seus direitos até aqui. Assim, foram adquirido o direito de se impor, votar, trabalhar e conquistando a proteção da lei. (EVANS, 2015).

Para Pitanguy:

as mulheres, ao longo dos séculos, têm sido privadas do exercício pleno de direitos humanos e têm sido submetidas a abusos e violências, tanto em situações de guerra, como no espaço da vida familiar e doméstica, elas têm tido um papel de grande relevância na ampliação do alcance dos direitos humanos. Questões que sempre fizeram parte da sua agenda, como a violência doméstica, os direitos sexuais e reprodutivos, direitos sociais específicos à mulher, a violação de sua integridade física, entre outros temas, vêm sendo colocadas por esses movimentos 
nas pautas de discussões das Nações Unidas e no âmbito nacional. As mulheres têm sido protagonistas nessa trajetória, seguindo dois caminhos complementares, um na esfera nacional e outro na arena internacional. (PITANGUY, 2010, p. 1).

A Constituição Federal de 1988 iguala a mulher ao homem em seu artigo $5^{\circ}$, caput, que prescreve que "todos são iguais perante a lei, sem distinção de qualquer natureza, garantindose aos brasileiros e aos estrangeiros residentes no País a inviolabilidade do direito à vida, à liberdade, à igualdade, à segurança e à propriedade, nos termos seguintes". (BRASIL, 1988).

Todavia, ainda que a Constituição proclame a igualdade entre homens e mulheres, a efetividade dessa previsão normativa é falha, uma vez que a cultura do patriarcado ainda está muito enraizada na população, de forma que continua sendo desigual o tratamento dispensado aos gêneros.

Na luta por igualdade, segundo Moreno, a Lei Maria da Penha:

criou mecanismos para coibir a violência doméstica e familiar contra a mulher, nos termos do art. 226 da Constituição Federal, da Convenção sobre a Eliminação de Todas as Formas de Discriminação contra as Mulheres e da Convenção Interamericana para Prevenir, Punir e a Violência contra a Mulher; dispõe sobre a criação dos Juizados de Violência Doméstica e Familiar contra a Mulher; altera o Código de Processo Penal, o Código Penal e a Lei de Execução Penal; e dá outras providências. (MORENO, 2014, p. 2).

Tal Lei possuiu um papel muito importante na sociedade brasileira, dando atenção para crimes domésticos e sendo base para a promoção de diversas campanhas a favor da proteção da mulher.

Nesse sentido, Moreno argumenta que:

[...] a Lei Maria da Penha representou uma verdadeira guinada na história da impunidade. Por meio dela, vidas que seriam perdidas passaram a ser preservadas; mulheres em situação de violência ganharam direito e proteção; fortaleceu-se a autonomia das mulheres. Com isso, a lei cria meios de atendimento humanizado às mulheres, agrega valores de direitos humanos à política pública e contribui para educar toda a sociedade (MORENO, 2014, p. 4).

Portanto, a função da lei é mostrar que o crime será punido severamente, de modo que sirva de alerta para os agressores.

Diante disso, a principal finalidade da Lei Maria da Penha é:

[...] é proporcionar instrumentos que "coibir, prevenir e erradicar" a violência doméstica e familiar contra a mulher, garantindo sua integridade física, psíquica, sexual, moral e patrimonial, a conhecida violência de gênero. (MORENO, 2014, p. 4). 


\section{O FEMINICÍDIO E OS DIREITOS CIVIS E UNIVERSAIS DAS MULHERES}

Muitas mulheres vivem diariamente situações de violência doméstica, mesmo sem perceber conscientemente as agressões que sofrem, já que muitos relacionamentos abusivos fazem com que a vítima sofra violência diariamente sem nem mesmo notá-la. (SAFFIOTI, 2004).

Nesse contexto, a Lei do Feminicídio foi inserida no Código Penal Brasileiro como tentativa de enrigecer a punição aos agressores e, via de consequência, conferir proteção às mulheres vítimas de violência doméstica contínua, assim como objetiva a Lei Maria da Penha.

Contudo, é importante abordar que a Lei do Feminicídio diverge da Lei da Maria da Penha, já que a primeira é uma qualificadora de crime violento contra a mulher e a Lei Maria da Penha, por sua vez, visa proteger a mulher da agressão física, psicológica, moral, sexual e patrimonial, ou seja, ela tem como objetivo impedir que o feminícidio aconteça. (PASINATO, 2011).

Pasinato conceitua feminicídio como:

[...] outra característica que define femicídio é não ser um fato isolado na vida das mulheres vitimizadas, mas apresentar-se como o ponto final em um continuum de terror, que inclui abusos verbais e físicos e uma extensa gama de manifestações de violência e privações a que as mulheres são submetidas ao longo de suas vidas. Sempre que esses abusos resultam na morte da mulher, eles devem ser reconhecidos como femicídio (PASINATO, 2011, p. 224).

Assim, o feminicídio passou a ser tipificado e conceituado no Código Penal, o que representa um avanço legislativo muito importante.

Gabriela Sales Toledo (2018) conceitua, ainda, o feminicídio como o:

[...] assassinato de mulheres apenas pelo fato de pertencer ao sexo feminino, dando a este um conceito político, com o propósito de denunciar a falta de resposta do Estado, o descumprimento de suas obrigações internacionais de proteção, e o dever de investigar e punir. O Feminicídio é um neologismo criado a partir da palavra em inglês "Femicide" que se refere à morte evitável de mulheres por razões de gênero, quer ocorra no núcleo familiar, na unidade doméstica ou em qualquer outra relação interpessoal na comunidade. (TOLEDO, 2018, p. 2).

A mesma autora divide o crime em dois aspectos: ativo ou direto e passivo ou indireto. O passivo ou indireto acrescenta ao feminicídio mortes como resultado de uma discriminação 
de gênero que não constitui delito, ou seja, são fatos que acontecem pelo simples fato de uma mulher pertencer ao gênero feminino. (TOLEDO, 2018).

O crime de feminicídio foi inserido no Código Penal com a Lei de $n^{\circ} 13.1104$ e está previsto art. $121, \S 2^{\circ}$, inciso VI, sendo uma modalidade de homicídio qualificado. (BRASIL, 1940).

Insta salientar que a qualificadora se refere a homicídios praticados no ambiente doméstico e a qualquer discriminação que envolva a mulher.

Logo, ao reconhecer o feminicídio como um crime hediondo, objetiva-se coibir a violência contra o gênero feminino, assegurando às mulheres direitos e garantias fundamentais. Dessa forma, a tipificação através da Lei n ${ }^{\circ}$ 13.104/2015 fornece uma transformação jurídica e social na consciência coletiva e um dispositivo de proteção às mulheres. (PINHEIRO, 2018).

Apesar desses marcos legais importantes para o combate à violência contra as mulheres, as medidas tomadas pelo Estado brasileiro para interromper esse processo são muito recentes em relação a outros países, e os números nacionais continuam alarmantes.

Para muitos autores, o número de feminicídios, mesmo sendo reconhecido atualmente como um crime hediondo, evidencia que a violência está enraizada nas estruturas sociais e no patriarcado. Dessa forma, muito ainda deve ser investido em políticas públicas para a proteção da mulher e para a desconstrução da estrutura patriarcal e da violência que esta emprega, sendo imperativo para o alcance da igualdade de gênero. (BRASIL, 2015).

\section{CONCLUSÃO}

É proibida pela Constituição Federal de 1988 toda e qualquer forma de discriminação contra as mulheres, sendo um dos objetivos fundamentais da República promover o bem de todos, sem preconceitos de origem, raça, sexo, cor, idade e quaisquer outras formas de discriminação.

Desta forma, é notável que a violência contra a mulher é circunstância que limita o seu acesso ao pleno desenvolvimento intelectual e profissional, à liberdade, à autonomia, à participação política, à educação e à saúde.

Nesse campo, vale ressaltar que a violência psicológica estabelecida na relação arbitrária de homens sobre mulheres perpassa a destruição emocional que se conhece e inavade a esfera dos direitos civis e universais da mulher, corrompendo-os. Tudo isso através de um sistema conhecido como patriarcado, enraizado na sociedade contemporânea através de séculos. 
Este sistema é um contrato ou pacto implícito de homens contra a igualdade de gênero e que não permite às mulheres o alcance da cidadania e dos seus direitos arrolados na Constituição Federal do Brasil e nos tratados internacionais de proteção à mulher.

Ainda, vê-se que a violência psicológica, pouco comentada, apesar de sua gravidade, é uma das violências primárias nas relações de abuso e que, em algum momento, pode resultar no feminicídio.

Dessa forma, nota-se que as relações de poder usam os mesmos mecanismos que Hannah Arendt menciona em seu livro Da Violência quando explica que para a manutenção de uma ideologia (política) e para a submissão de certos homens em detrimento de outros é necessária a força, de modo que a violência física é um instrumento usado quando todos os outros meios não forem o bastante.

Por isso, a violência psicológica se coloca a serviço da estrutura patriarcal como primeira expressão de violência, que coibe mulheres de alcançar a sua liberdade, autonomia e igualdade, sendo a violência física, e até o derradeiro feminicídio, a ferramenta final para garantir tais objetivos.

Por fim, fica claro que muito deve ser investido em políticas públicas para a proteção da mulher e para a descontrução da estrutura patriarcal e da violência que ela emprega, sendo imperativo para o alcance da igualdade entre os gêneros a garantia da aplicação das leis vigentes, com as devidas punições aplicadas, e a preocupação em assegurar a todas as mulheres seus direitos civis e universais conquistados a duras penas e diante de luta e resistência.

\section{REFERÊNCIAS BIBLIOGRÁFICAS}

ALVES, Fernando de Brito; RIGÃO, Livia Carla Silva. Cultura da periferia e as canções de rap: um olhar para as "vozes silenciadas" a partir da filosofia de Enrique Dussel. Revista Direitos Sociais e Políticas Públicas - Unifafibe. V. 8, N. 1, 2020.

ARENDT, Hannah. Eichmann em Jerusalém: um relato sobre a banalidade do mal. São Paulo: Companhia das

Letras, 1999.

. Sobre a violência. Rio de Janeiro: Relume-Dumará, 1994.

BEAUVOIR, Simone de. O segundo sexo: fatos e mitos. Tradução: Sérgio Milliet. 4. ed. São Paulo: Difusão Europeia do Livro, 1980.

BRASIL. Decreto-Lei $\mathbf{n}^{\mathbf{2}} \mathbf{2 . 8 4 8}$, de 7 de dezembro de 1940. Código Penal. Brasília, DF: Presidência da República, [1940]. Disponível em: 
http://www.planalto.gov.br/ccivil_03/decreto-lei/del2848compilado.htm. Acesso em: 3 jul. 2019.

Lei $\mathbf{n}^{\mathbf{0}}$ 11.340, de 7 de agosto de 2006. Cria mecanismos para coibir a violência doméstica e familiar contra a mulher, nos termos do $\S 8^{\circ}$ do art. 226 da Constituição Federal, da Convenção sobre a Eliminação de Todas as Formas de Discriminação contra as Mulheres e da Convenção Interamericana para Prevenir, Punir e Erradicar a Violência contra a Mulher; dispõe sobre a criação dos Juizados de Violência Doméstica e Familiar contra a Mulher; altera o Código de Processo Penal, o Código Penal e a Lei de Execução Penal; e dá outras providências. Disponível em: http://www.planalto.gov.br/ccivil_03/_ato20042006/2006/lei/111340.htm. Acesso em: 24 jul. 2019.

Ministério da Justiça. Secretaria da Reforma do Judiciário. Centro de Estudos sobre o Sistema de Justiça. Diálogos sobre Justiça. A violência doméstica fatal: o problema do feminicídio íntimo no Brasil. In: MACHADO, Martha Rodrigues de Assis (coord.). Brasília, DF: Ministério da Justiça, Secretaria da Reforma do Judiciário, 2015. Disponível em: https://www.justica.gov.br/seus-direitos/politicas-de-

justica/publicacoes/Biblioteca/publicacao_feminicidio.pdf/. Acesso em: 27 jul. 2019.

Senado Federal. Comissão Parlamentar Mista de Inquérito da Violência contra a Mulher. Com a finalidade de investigar a situação da violência contra a mulher no Brasil e apurar denúncias de omissão por parte do poder público com relação à aplicação de instrumentos instituídos em lei para proteger as mulheres em situação de violência. Relatório Final. Brasília, DF: Senado Federal, [2013]. Disponível em: https://www12.senado.leg.br/institucional/omv/entenda-a-violencia/pdfs/relatorio-final-dacomissao-parlamentar-mista-de-inquerito-sobre-a-violencia-contra-as-mulheres. Acesso em: 22 jul. 2019.

. [Constituição (1988)]. Constituição da República Federativa do Brasil de 1988. Brasília, DF: Presidência da República, [2016]. Disponível em: http://www.planalto.gov.br/ccivil_03/Constituicao/Constituiçao.htm. Acesso em: 6 jul. 2019.

CALCAGNO, Victor. Mais de 200 feminicídios ocorreram no país em 2019, segundo pesquisador. O Globo, 7 mar. 2019. Disponível em: https://oglobo.globo.com/sociedade/maisde-200-feminicidios-ocorreram-no-pais-em-2019-segundo-pesquisador-23505351. Acesso em: 27 jul. 2019.

CASTRO, Alexander; NASCIMENTO, Gabriel Bassaga. Liberdade de expressão frente à liberdade religiosa: direitos fundamentais em conflito e proteção de direitos da personalidade frente a discursos de ódio. Revista Direitos Sociais e Políticas Públicas - Unifafibe. V. 7, N. 3, 2019.

COSTA, Fabrício Veiga; PINTO, Alisson Alves. A ressocialização do detento a partir do prazo para o cumprimento da função social da empresa na sociedade contemporânea. Revista Direitos Sociais e Políticas Públicas - Unifafibe. V. 7, N. 3, 2019.

EVANS, Patricia. Como enfrentar a violência verbal: aprenda a se defender de relações abusivas. Rio de Janeiro: Sextame, 2015. 
FONSECA, Maria Fernanda Soares et al. O feminicídio como uma manifestação das relações de poder entre os gêneros. Juris, Rio Grande, v. 28, n. 1, p. 49-65, 2018. Disponível em: https://periodicos.furg.br/juris/article/viewFile/7680/5330. Acesso em: 15 ago. 2019.

FREUD, Sigmund. Estudos sobre a histeria. In: FREUD, Sigmund. Edição standard das obras psicológicas completas de S. Freud. Rio de Janeiro: Imago, 1976.

FERENCZI, Sándor. Palabras obscenas: contríbución a la psicología en el período de la latencia. In: FERENCZI, Sándor. Obras completas. Madrid: Espasa-Calpe, 1981. p. 135-147.

HERMANN, Leda Maria. Maria da Penha Lei com nome de mulher: considerações à Lei n. ${ }^{\circ}$ 11.340/2006: contra a violência doméstica e familiar, incluindo comentários artigo por artigo. Campinas: Servanda,2008.

LAZCANO, Alfonso Jaime Martínez. El derecho convencional y los retos de su implementación en los estados parte. Revista Direitos Sociais e Políticas Públicas Unifafibe. V. 7, N. 3, 2019.

LOZANO, Luis Gerardo Rodrígues León duguit y el servicio público: ideas para el siglo XXI. Revista Direitos Sociais e Políticas Públicas - Unifafibe. V. 8, N. 1, 2020.

LUCAS, Doglas Cesar. Direitos humanos, identidade e a política de reconhecimento de Charles Taylor. Revista Direitos Sociais e Políticas Públicas - Unifafibe. V. 7, N. 3, 2019.

MAGLIACANE, Alessia. L'armee des reserves dans la mondialisation : la parabole de la femme italienne de la constitution au post-fordisme. Revista Direitos Sociais e Políticas Públicas - Unifafibe. V. 7, N. 3, 2019.

MAO TSÉ-TUNG. Citações do Presidente Mao Tsé-Tung. São Paulo: Edições Seara Vermelha, 2016.

MARCONDES FILHO, Ciro. Violência fundadora e violência reativa na cultura brasileira. São Paulo: Perspectiva, 2001.

MARTÍN, Ignacio Durbán Origen y fundamentos del sistema plurilegislativo civil español. Revista Direitos Sociais e Políticas Públicas - Unifafibe. V. 8, N. 1, 2020.

MORAES, Maria Valentina de; LEAL, Mônia Clarissa Hennig. Supremo tribunal federal e diálogo institucional: há um controle jurisdicional de políticas públicas no brasil? Revista Direitos Sociais e Políticas Públicas - Unifafibe. V. 7, N. 3, 2019.

MORENO, Renan de Marchi. Eficácia da Lei Maria da Penha. Conteúdo Jurídico, 20 nov. 2014. Disponível em: https://www.direitonet.com.br/artigos/exibir/8757/A-eficacia-da-LeiMaria-da-Penha. Acesso em: 15 ago. 2019.

PEREIRA, Rodrigo da Cunha. Direito de Família: uma abordagem psicanalítica. Belo Horizonte: Del Rey; IBDFAM, 2003.

PITANGUY, Jacqueline. Os direitos humanos das mulheres. Fundo Brasil de Direitos Humanos. São Paulo, 2010. Disponível em: 
https://www.fundodireitoshumanos.org.br/downloads/artigo_mulheres_jacpit.pdf. Acesso em: 15 ago. 2019.

RÍOS, Carlos Castillo. La Educación en China: una pedagogia revolucionaria. Buenos Aires: Búsqueda, 1973.

SAFFIOTI, Heleieth lara Bongiovani. Gênero, patriarcado, violência. São Paulo: Fundação Perseu Abramo, 2004.

SAKAGAMI, Amanda da Silva. Ampliação da Proteção das vítimas do crime de feminicídio às mulheres transexuais e travestis. 2018. $22 \mathrm{f}$. Trabalho de Conclusão de Curso (Graduação em Direito) - Centro Universitário de Maringá, Maringá, 2018. Disponível em: http://rdu.unicesumar.edu.br/bitstream/123456789/734/1/tcc.pdf. Acesso em: 27 jul. 2019.

SARTRE, Jean Paul. Questão do Método. In: PESSANHA, J. A. M. Sartre. 3. ed. São Paulo: Nova Cultural, 1987. (Coleção Os Pensadores).

SCOTT, Joan. Wallach. Gênero: uma categoria útil de análise histórica. Educação \& Realidade, v. 91, n. 5, p.71-99, jul./dez. 1995.

TOZATTI, Adriana Quintino Sanchez Palacio; ALMEIDA, Vivian Fernandes Carvalho de. A violência contra a mulher na cidade de Maringá. In: MOSTRA INTERNA DE TRABALHOS DE INICIAÇÃO CIENTÍFICA, 9., MOSTRA INTERNA DE INICIAÇÃO EM DESENVOLVIMENTO TECNOLÓGICO E INOVAÇÃO, 2., 2018, Maringá. Anais [...]. Maringá, 2018. Disponível em: https://www.unicesumar.edu.br/mostra-2018/wpcontent/uploads/sites/204/2018/11/adriana_quintino_sanchez_palacio_tozatti.pdf. Acesso em: 27 jul. 2020.

WALD, Arnold. O novo Direito de Família. 14. ed. São Paulo: Saraiva, 2002.

Trabalho recebido em 31 de julho de 2019 Aceito em 21 de abril de 2021 